\title{
The Influence of Air Temperature on the Dew Point Temperature in Benin City, Nigeria
}

\section{${ }^{* 1}$ UKHUREBOR, KE; ${ }^{2}$ BATUBO, TB; ${ }^{3}$ ABIODUN, IC; ${ }^{4}$ ENOYOZE, E}

\author{
${ }^{I}$ Department of Physics, Edo University, Lyamho, Edo State, Nigeria \\ ${ }^{2}$ Department of Mathematics, University of Benin, Benin City, Edo State, Nigeria \\ ${ }^{3}$ Department of Physics, Federal University, Otuoke, Bayelsa State, Nigeria \\ ${ }^{4}$ Department of Mathematics, Edo University, Iyamho, Edo State, Nigeria \\ "Corresponding Author: ukeghonghon@gmail.com; +2348035383194
}

\begin{abstract}
Research in weather measurement, monitoring and prognostications are becoming more and more pertinent in this era of global warming; getting the appropriate weather predictions and taking the necessary precautions have become very paramount. This research shows the influence of air temperature on the dew point temperature in Benin City, Edo State, Nigeria. The dew point temperature was approximated from the measured air temperature and relative humidity with the aid of a self-designed weather monitoring system in 2016 and the regression equation was obtained using the curve estimation procedure from SPSS 18.0 for Windows and Microsoft Excel version 7. The finding shows that the air temperature and the dew point temperature have a linear relationship and that the air temperature has a significant influence on the dew point temperature; an increase in the air temperature would also result in an increase in the dew point temperature and this would help in the alleviation of climateinduced environmental disasters, improvement in agricultural productivity and also for spatial planning in our communities. It is therefore, recommended that further research work should be done to determine the influence and effect of temperature on other climatic environmental parameters. () JASEM https://dx.doi.org/10.4314/jasem.v21i4.5
\end{abstract}

Key words: Air Temperature, Dew point temperature, Weather, Climate, Influence

Weather monitoring and prediction has developed over the centuries and a lot of knowledge and information have been gathered that have helped in the understanding and studying of weather.Significantly, weather has always had influence the lives of people and shaped their cultures, beliefs, habits, attitudes, behaviour and their environments in general. Taking weather and trying to predict it appropriately can make a difference for the survival and prosperity of the human race.Weather is mostly influenced by the following factors: location latitude, elevation and proximity to water bodies (Karl, 2014).

Weather has always been a universal concern and the recent and present change in the climate is becoming an issue, in particular. It's monitoring holds great importance and has uses in several areas ranging from keeping track of agricultural field weather conditions to industrial weather conditions monitoring. Its measurement and monitoring would help in keeping track of different climatic behaviors including temperature, humidity, atmospheric pressure, light intensity, altitude, dew point, precipitation and other parameters (Akhilesh et.al, 2015)

There cannot be a study of the weather neither its prognostication without the knowledge of the prevailing conditions of the atmosphere. For this reason, man has always implored and devised means of measuring different elements of the weather.With the advancement of technology, new methods and equipment have been developed to measure, collect and monitor weather information and today a whole field of study; Meteorology is dedicated to it. Meteorology is the science of the atmosphere. Its domain is the atmosphere of the whole universe and its practice involves the daily cooperation of every action on the universe. In meteorology, the data measured and collected are used in monitoring and forecasting the weather; which are useful in one way or the other in the course of our daily activities. Meteorologically, weather is used to describe the momentary atmospheric conditions at a certain place. It is the state of the atmosphere of a given place at a particular time. Weather describes the condition of the atmosphere over a short period of time for example, from day to day or week to week. The climate of an area is known through the average weather over a long period of time. If an area has more dry days throughout the year than wet days, it would be described as a dry climate and if a place have more cold days than hot days it would be known to have a cold climate. Climate describes the average weather conditions over a longer period of time. In describing the atmospheric conditions of a given place at a given time, certain weather elements or parameters must be known, measured and quantified. Some of the most crucial weather elements are temperature, relative humidity, atmospheric pressure, 
wind speed and direction, precipitation, dew point, altitude, solar or light intensity.

Temperature is a comparative measure of the thermal state. Itis how hot or cold the atmosphere may be. There are several scales and units for measuring temperature; the Celsius/Centigrade scale $\left({ }^{0} \mathrm{C}\right)$, Rankine scale $\left({ }^{0} \mathrm{R}\right)$, Fahrenheit scale $\left({ }^{0} \mathrm{~F}\right)$ and Absolute Temperature scale/Kelvin (K). Temperature is a widely measured variable and is a very critical factor in determining the weather; because it influences or controls other elements of the weather, such as the dew point temperature, precipitation, humidity, clouds and atmospheric pressure. Its measurements have encompasses a wide variety of needs and applications (Akhileshet.al, 2015; Dushyant and Sanjeev, 2013).

The dew point temperature is the temperature at which the moisture/liquid water (water vapor) in the air begins to condense or evaporates at same rate at which it condenses. Dew point is of great interest to meteorologists because it is a fundamental measure of the state of the atmosphere in terms of how much water vapor is present (Raymond, 1991).Furthermore, dew point temperature can provide a fairly direct sense of how comfortable or uncomfortable warm air will feel. Dew point can also give us a reasonable starting point for estimating low temperatures the following day, as under certain conditions the low will end up pretty close to the dew point at the time of maximum temperature the day before. We can also use projections of dew point temperature to aid in prognosticating the formation of fog or dew and in the estimating rain, snow, dew, evapotranspiration, near-surface humidity and other meteorological parameters. Also, higher dew points through the lower atmosphere (especially those above $60^{\circ}$ or so) can help to support more numerous and/or intense thunderstorms when other factors favor their formation. The dew point is directly related to the amount of water vapour; it's directly proportional to water vapour (Mike, 2016).

Man has always tried to find out the causes of different weather conditions he finds himself in and possibly monitor and forecast what the weather would be at any given time (Karl, 2014; Akpan et.al, 2016). Hence, this research would help guide against the occurrences of climate induced environmental disasters and also improve agricultural productivity in our communities.

\section{MATERIAL AND METHOD}

Spontaneous measurement for air temperature and relative humidity were carried out in Benin City, the capital of Edo State in Southern Nigeria which is situated approximately $40 \mathrm{~km}$ north of the Benin River and $320 \mathrm{~km}$ by road east of Lagos located on latitude $6^{\circ} 20^{\prime} 17^{\prime \prime} \mathrm{N}$, longitude: $5^{\circ} 37^{\prime} 32^{\prime \prime}$ Eat elevation
88 meters above sea level has an approximate population of 1,125,058 making it the biggest city in Edo State. It operates on the West Africa time zone simultaneously at approximate height of $1.5 \mathrm{~m}$ above sea level. The readings were made every hour from 8.00 am to $6.00 \mathrm{pm}$ during the period of January 2016 to December 2016 using a self-designed cost effective weather monitoring system and the dew point temperature was approximated from using the Thumb rule. The data were analyzed using the computer packages SPSS 18.0 for Windows and Microsoft Excel version 7. The regression equation was obtained using the curve estimation procedure.

\section{RESULTS AND DISCUSSION}

Table 1 and Table 2 are the measured air temperature and relative humidity respectively and the parameters were in good conformity with weather data obtained from other sources (the Nigerian Meteorological Agency; NMA and online weather reports).

Table 1 Air Temperature for 2016

\begin{tabular}{ll}
\hline Month & Measured Average Temperature $\left({ }^{\circ} \mathrm{C}\right)$ \\
& \\
January & 25.00 \\
February & 30.00 \\
March & 30.00 \\
April & 28.00 \\
May & 27.00 \\
June & 26.00 \\
July & 26.00 \\
August & 26.00 \\
September & 26.00 \\
October & 27.00 \\
November & 27.00 \\
December & 23.00 \\
Mean Total & 26.80 \\
\hline
\end{tabular}

Table 2 Relative Humidity for 2016

\begin{tabular}{ll} 
Month & Measured Average Humidity $(\%)$ \\
& \\
January & 40.00 \\
February & 48.00 \\
March & 78.00 \\
April & 85.00 \\
May & 92.00 \\
June & 92.00 \\
July & 95.00 \\
August & 78.00 \\
September & 78.00 \\
October & 68.00 \\
November & 68.00 \\
December & 58.00 \\
Mean Total & 73.30 \\
\hline
\end{tabular}

Thereafter, the approximation of the dew point temperature using the Thumb rule (Eqn. 1) and (Eqn. 2) was carried out. Table 3 contained the approximated dew point temperature from the measured temperature and relative humidity accordingly and they were also in conformity with that from other sources. 


$$
T d=T-\left(\frac{100-R H}{5}\right)
$$

Also we can use a complex formula;

$$
T d=\operatorname{Tn} \frac{I n\left(\frac{R H}{100}\right)+\left(\frac{m T}{T n}+T\right)}{m-I n\left(\frac{R H}{100}\right)-\left(\frac{m T}{T n}+T\right)}
$$

Where $T d$ is the dew point, $T$ is the temperature, $R H$ is the relative humidity. For the temperature range $-40^{\circ} \mathrm{C}$ to $0^{\circ} \mathrm{C}, T n=272.62^{\circ} \mathrm{C}$ and $m=22.46$ while for the temperature range $0^{\circ} \mathrm{C}$ to $50^{\circ} \mathrm{C}, T n=243.12^{\circ} \mathrm{C}$ and $m=17.62$.

The dew point value can also be calculated automatically from the computer using MATLAB after receiving the temperature and relative humidity values or through online calculator Dushyant and Sanjeev, 2013; Roneel, 2014).

Table 3 Dew Point Temperature for 2016

\begin{tabular}{ll}
\hline Month & Approximated Average Dew Point $\left({ }^{\circ} \mathrm{C}\right)$ \\
& \\
January & 13.00 \\
February & 19.60 \\
March & 25.60 \\
April & 25.00 \\
May & 25.40 \\
June & 24.40 \\
July & 26.00 \\
August & 21.60 \\
September & 21.60 \\
October & 20.60 \\
November & 20.60 \\
December & 14.60 \\
Mean Total & 19.70 \\
\hline
\end{tabular}

The mean total air temperature for the year 2016 was found to be $26.80^{\circ} \mathrm{C}$ while the mean total dew point temperature was $19.70^{\circ} \mathrm{C}$. The results of this study also showed that the dew point temperature for Benin City, Edo State, Nigeria were low during the months of January, 2016 and December, $2016\left(13.00^{\circ} \mathrm{C}\right.$ and $14.60^{\circ} \mathrm{C}$ respectively) which were also the months of the air temperature $\left(25^{\circ} \mathrm{C}\right.$ and $23^{\circ} \mathrm{C}$ respectively) have the lowest values. The highest level of the dew point temperature $\left(26.00^{\circ} \mathrm{C}\right)$ was in the month of July, 2016 and the highest air temperature $\left(30^{\circ} \mathrm{C}\right)$ were during the months of February and March, 2016 which are the months of the peak of the dry season.

Trend graphs of air temperature and the dew point temperature against the months were drawn and scatter plots of air temperature against the dew point temperature were fitted and are shown in Figure 1 and Figure 2 respectively. The regression equation was obtained using the curve estimation procedure to determine the relationship between air temperature and the dew point temperature for Benin City, Edo State, Nigeria from the pooled data.

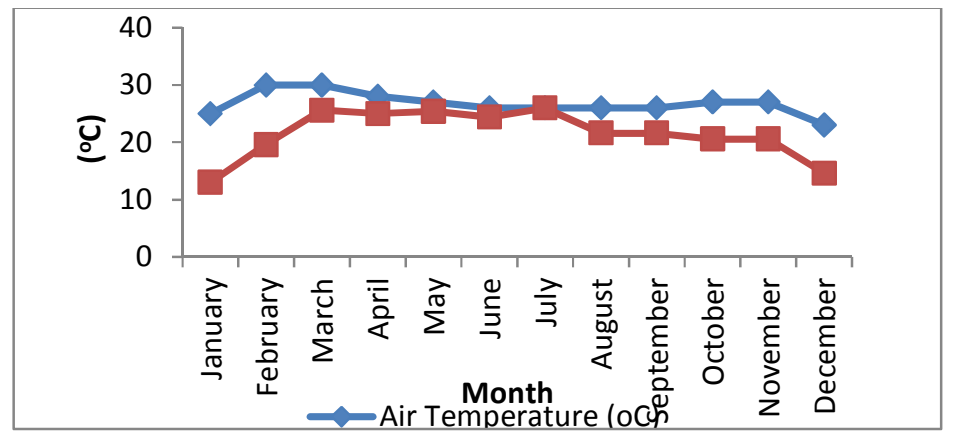

Fig 1: The trend graph for the Air Temperature $\left({ }^{\circ} \mathrm{C}\right)$ and Dew Point

Temperature $\left({ }^{\circ} \mathrm{C}\right)$ at Benin City, Nigeria for 2016 


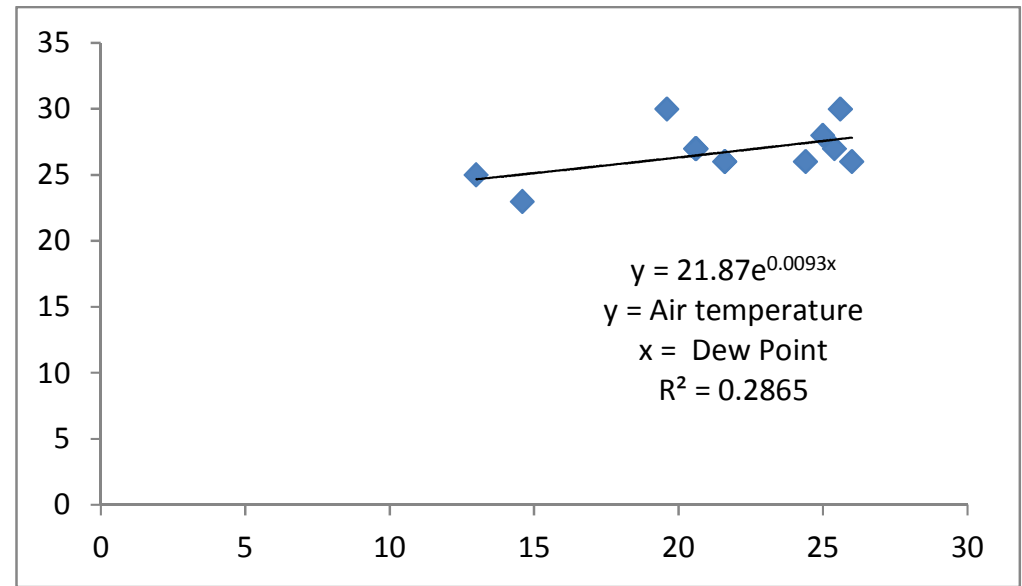

Fig 2: The relationship between the Air Temperature $\left({ }^{\circ} \mathrm{C}\right)$ and Dew Point Temperature $\left({ }^{\circ} \mathrm{C}\right)$ at Benin City, Nigeria for 2016

From the analysis above we therefore arrived at the finding that the relationship between air temperature and the dew point temperature are linear and that the air temperature has a significant influence on the dew point temperature; an increase in the air temperature would also result in an increase in the dew point temperature.

The relationship between the air temperature and the dew point temperature established in this research was in conformity with some other findings like the work of Akhilesh, 2015; Dushyant and Sanjeev, 2013.

Accurate measurement, monitoring and proper observation of the various weather parameters would in no doubt help guide against the occurrences of climate induced environmental disasters in our community (Okhakhu, 2014).

Conclusion: The research has further shows the influence on temperature on other atmospheric weather parameters. It was observe that an increase in the air temperature would also result in an increase in the dew point temperature. Hence, this would help guide against the occurrences of climate induced environmental disasters and also improve agricultural productivity in our communities. We therefore recommend that further research work should be done to determine the influence and effect of temperature on other climatic environmental parameters.

Acknowledgement: The authors are grateful to Mrs. UK-Eghonghon Gladys for her assistance during the measurement process.

\section{REFERENCES}

Akhilesh, C; TejasBangera,C K; Mahalaxmi, B (2015).Bluetooth Based Weather Station International Journal of Engineering Trends and Technology (IJETT) - Vol. 28 Number 2.
Dushyant, P; Sanjeev, G (2013).Measurement And Transmission Of Atmospheric Parameters Using Radio Frequency Communication International Journal Of Technical Research And Applications E-ISSN: 2320-8163, Volume 1, Issue 3,Page8590.

Karl,I E (2014).Portable Weather Station Final thesis for B.Sc. degree School of Engineering and Natural Sciences, Keilir Institute of Technology University of Iceland Reykjanesbar.

Mike, M (2016). Capitol Broadcasting Company, Raleigh, North Carolina, USA.

Okhakhu,P.A (2014). Meteorological Services for Disaster Risk Prevention and MitigationNigeria Journal of Environment and Earth Science ISSN 2224-3216 (Paper) ISSN 2225-0948 (Online) Vol.4, No.8.

Raymond. A. S. (1991).College Physics, Saunders College Publishing, Harrisonburg, Virginia, USA.

Roneel, V S(2014).Development of a Remote Automatic Weather Station with a PC-based Data LoggerInternational Journal of Hybrid Information Technology Vol.7, No.1 pp.233-240 http://dx.doi.org/10.14257/ijhit.2014.7.1.19 ISSN: 1738-9968 IJHIT.

Vincent, AA; Reginald, O A O; Sylvester, A E (2016). A Hypothetical Database-Driven WebBased MeteorologicalWeather Station with Dynamic Datalogger SystemJournal of Information Engineering and ApplicationsISSN 2224-5782 (print) ISSN 2225-0506 (online) Vol.6, No.1. 